\section{Primary care reform}

We want to thank Dr. Barbara Starfield for her insightful commentary about our paper in CMAJ May 26. While we agree with the issues she raised, her article contains a misleading statement that the higher rate of visits to emergency departments in capitation was observed only in rural areas. This appears to be the case in Table 4 of the print version, which was not adjusted for provider or patient characteristics. In the online version, however, we state that "after adjustment for physician and patient characteristics, we found that patients in capitation practices continued to have higher rates of use of emergency department services than patients in enhanced fee-for-service practices. This finding was consistent and significant across all 3 geographic locations." Not presented in the paper were the values adjusted for physician and patient.

\section{Richard H. Glazier MD}

Senior Scientist, Institute for Clinical Evaluative Sciences, Toronto, Ont.

For the full letter, go to:

www.cmaj.ca/cgi/eletters/180/11/1091\#136900

DOI:10.1503/cmaj.091104

\section{The author responds:}

The clarification by Dr. Glazier is appropriate. Although controlling for patient characteristics eliminates and explains the reason for the excess use of emergency care in rural areas, the fact is that there is something different about the needs of people in rural areas for emergency care services.

\section{Barbara Starfield MD MPH}

University Distinguished Professor, Johns Hopkins University, Baltimore, MD, USA

DOI:10.1503/cmaj.091111

\section{No options for sleep}

Re: Sleepless in the surgical ward, news, May 26; Must we keep depriving residents of sleep?, editorial, May 26
It always struck me as odd when a resident claims that they believe they should be able to 'choose' to work longer hours that violate current maximums if they perceive education benefit of doing so. The limits on residents' work hours are not only to protect residents; they are also to protect patients. The maximum work-hours limits should not be optional for residents; they should be mandatory.

\section{Mark Otto Baerlocher}

Post-graduate year 4, Radiology residency training program, University of Toronto,

Toronto, Ont.

For the full letter, go to:

www.cmaj.ca/cgi/eletters/180/11/1095\#137682

DOI:10.1503/cmaj.091105

\section{Correction}

The May 26 research article "Benefits and harms of erythropoiesis-stimulating agents for anemia related to cancer: a meta-analysis" suggested that none of the studies that reported mortality used erythropoiesis-stimulating agents in a manner consistent with the current Health Canada label for darbepoetin. That was incorrect. The paragraph should read as follows:

Current practices for the use of erythropoiesis-stimulating agents in people with cancer-related anemia are more restrictive than they once were. Guidelines from the American Society of Clinical Oncology indicate that the agents should not be used unless patients are receiving concurrent chemotherapy; however, they cautiously recommend their use when the hemoglobin level is less than or ap- proaching $100 \mathrm{~g} / \mathrm{L}$ (or $100-120 \mathrm{~g} / \mathrm{L}$ in certain circumstances, including decreased cardiopulmonary reserve). The recently revised Health Canada label for darbepoetin is similar to the society's criteria: it indicates that the agent should be used for cancer-related anemia under very specific conditions: the presence of nonmyeloid cancer; anemia due to chemotherapy; a hemoglobin level less than $100 \mathrm{~g} / \mathrm{L}$; and a target hemoglobin level of no more than 120 $\mathrm{g} / \mathrm{L}$. Although we identified 2 studies that reported mortality and met the last 3 conditions (and were therefore consistent with the American Society of Clinical Oncology's criteria), both enrolled patients with a hematological malignancy (multiple myeloma).

\section{REFERENCE}

1. Tonelli M, Hemmelgarn B, Teiman T, et al. Benefits and harms of erythropoiesis-stimulating agents for anemia related to cancer: a meta-analysis. CMAJ 2009;180(11):E62-E71.

For the full paper, go to: www.cmaj.ca/cgi/content/full/180/11/E62

DOI:10.1503/cmaj.091106

\section{Letters to the editor}

In submitting a letter, you automatically consent to have it appear online and/or in print. All letters accepted for print will be edited by CMAJ for space and style. Most references and multiple authors' names and full affiliations will appear online only. (The full version of any letter accepted for print will be posted on the website.) 